\title{
Formation of precipitates in parallel arrays on LPSO structures during hot
} deformation of GZ41K magnesium alloy

Mohammad Saadati ${ }^{\mathrm{a}}$, Rasoul Azari Khosroshahi ${ }^{\mathrm{a}, *}$, Gholamreza Ebrahimi ${ }^{\mathrm{b}}$, Mohammad Jahazi ${ }^{\mathrm{c}, *}$

${ }^{a}$ Faculty of Materials Engineering, Sahand University of Technology, Tabriz, Iran

b Materials and Polymers Engineering Department, Faculty of Engineering, Hakim Sabzevari University, Sabzevar, Iran

c Département de Génie Mécanique, École de Technologie Supérieure, 1100 Rue Notre-Dame Ouest, Montreal H3C 1K3, Canada

Authors' accepted manuscript

Article published in Materials Characterization vol. 131 (2017)

https://doi.org/10.1016/j.matchar.2017.07.007

(C) 2017. Made available under the CC-BY-NC-ND 4.0 license

http://creativecommons.org/licenses/by-nc-nd/4.0/ 


\title{
Formation of precipitates in parallel arrays on LPSO structures during hot deformation of GZ41K magnesium alloy
}

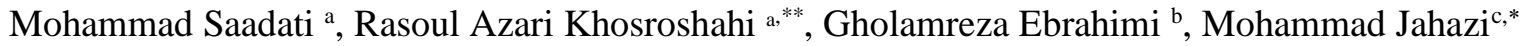 \\ ${ }^{a}$ Faculty of Materials Engineering, Sahand University of Technology, Tabriz, Iran \\ ${ }^{b}$ Materials and Polymers Engineering Department, Faculty of Engineering, Hakim Sabzevari University, Sabzevar, Iran \\ ${ }^{c}$ Département de Génie Mécanique, École de Technologie Supérieure, 1100 Rue Notre-Dame Ouest, Montreal, H3C 1K3, \\ Canada
}

\begin{abstract}
$(\mathrm{Mg}, \mathrm{Zn})_{3} \mathrm{Gd}$ precipitates were observed in the form of parallel arrays within a $\alpha-\mathrm{Mg}$ matrix of a $\mathrm{Mg}-3.5 \mathrm{Gd}-1 \mathrm{Zn}-0.6 \mathrm{Zr}$ $(\mathrm{GZ41K})$ alloy following isothermal holding at $450{ }^{\circ} \mathrm{C}$ for $20 \mathrm{~min}$ or uniaxial hot compression testing at $450{ }^{\circ} \mathrm{C}$ and at strain rates of $10^{-3} \mathrm{~s}^{-1}$ and $10^{-1} \mathrm{~s}^{-1}$. A microstructural analysis using a combination of scanning and transmission electron microscopies showed arrays of precipitates nucleated on stacking faults as a result of the LPSO structures decomposing statically after long isothermal holding times at $450{ }^{\circ} \mathrm{C}$, which is lower than the dissolution temperature of $(\mathrm{Mg}, \mathrm{Zn})_{3} \mathrm{Gd}$ precipitates $\left(520^{\circ} \mathrm{C}\right)$, and dynamically, as a result of hot compression. The presence of precipitates on slip bands was also observed in the case of deformed specimens. The characteristics of the precipitates were investigated using differential thermal analysis, and optical and electron microscopy. The influences of the solutionizing temperature and deformation conditions on distribution, morphology and volume fraction of precipitates were quantified. The results are interpreted in terms of the influence of the strain rate in increasing the stacking fault/dislocation intersections and the decomposition of the $\mathrm{L}_{2}$ structure of stacking faults.
\end{abstract}

Keywords: Magnesium alloys; LPSO; Precipitation; Stacking faults; Slip band

\footnotetext{
* Corresponding author. Département de Génie Mécanique, École de Technologie Supérieure, 1100 Rue NotreDame Ouest, Montreal, H3C 1K3, Canada

E-mail address: mohammad.jahazi@etsmtl.ca (M. Jahazi), Tel: +1 514 396-8974

*** Corresponding author. Faculty of Materials Engineering, Sahand University of Technology, Tabriz, Iran E-mail address: rakhosroshahi@sut.ac.ir (R. Azari Khosroshahi)
} 


\section{Introduction}

Magnesium and its alloys, as lightest engineering alloys, have attracted intense interests in recent years because of their low density and high specific strength. However, these alloys suffer from room temperature ductility mainly due to the limited active slip systems inherent to the $\mathrm{HCP}$ structure of Magnesium, the large grain size especially in the as-cast state, and the presence of abundant precipitates in the matrix. Application of as-cast $\mathrm{Mg}$ alloys is also limited in particular for ternary, quaternary alloy systems due to the formation of multiple eutectics during solidification which provide inhomogeneous microstructures. Hot deformation processes are recognized as effective methods that result in a better distribution of second phases, elimination of eutectic structure, and enhancement in mechanical properties of $\mathrm{Mg}$ alloys through precipitation and grain refinement by dynamic recrystallization [1-3]. Specifically, solutionizing heat treatments before hot deformation which produce supersaturated solid solutions (SSS), improve the formability of Mg alloys [4]. Moreover, Formation of deformation-induced precipitates from a SSS during hot deformation, provides grain refining through pinning or decelerating the movement of sub grain boundaries and/or dynamically recrystallized (DRXed) grain boundaries and consequently enhances the strength of the alloy [5].

Among the emerging Mg alloys with enhanced mechanical properties, Mg-TM-RE alloys (TM and RE are transition and rare-earth elements, respectively) are the most promising ones [6-9]. Specially Mg-Zn-Y and Mg-Zn-Gd alloys containing Long Period Stacking Ordered (LPSO) structures have been the subject of increased attention as they possess excellent mechanical properties (e.g. UTS >400MPa, and elongation>5\%) [10-13]. Formation of LPSO structures have already been reported in as-cast, heat treated, or hot deformed conditions and it is now accepted that their characteristics including their stability are strongly dependent on the type and 
concentration of the RE element $[14,15]$. Although, the presence of some LPSO structures have been reported in as-cast $\mathrm{Mg}-\mathrm{Gd}-\mathrm{Zn}$ alloy systems [16, 17], their stability over time is still an issue and most of the stable LPSO structures, especially at low Gd contents, have been produced through heat treatment or during hot deformation of these alloys $[1,18]$. However, in the above studies the only phase present in the $\alpha-\mathrm{Mg}$ matrix has been the LPSO structure and the influence of other secondary phases such as $\mathrm{W}$-phase or $\mathrm{Mg}_{5} \mathrm{Gd}$ and etc. has not been considered.

The formation mechanism of the LPSO structures is still subject of debate and in recent years many efforts have been devoted to elucidating the mechanism of LPSO formation both through experimental or mathematical modeling [19-21]. Specifically, Iikubo et al. [19] reported that increasing vibrational entropy and weakening of the $\mathrm{Mg}-\mathrm{Mg}$ bond strength (i.e. lattice expansion) promote the formation of LPSO structure. Lattice expansion could occur by thermal volume expansion or introduction of large solute atoms in substitutional positions. The expansion, results in increased generation of stacking faults between the stacking sequences of the magnesium lattice. The higher is the number of stacking faults, the larger is the vibrational entropy [20]. Moreover, solute elements which decrease the intrinsic stacking fault energy and are necessary for LPSO formation, diffuse easier by an increase in the vibrational entropy. As the formation of a stacking sequence in a $\mathrm{HCP}$ structure $(\mathrm{ABAB} .$.$) is of a FCC stacking type (ABCAB...) therefore, reduction$ in the SFE of the lattice, encourages the formation of FCC layers [21]. The interface of this FCC layer and the original HCP region, has a negative energy. Besides, solute elements can segregate toward the FCC layer of SF to form initially disordered FCC and finally ordered $\mathrm{L}_{2}$ clusters. However, according to thermodynamic calculations [7, 22], the presence of LPSO structure is extremely dependent on the $\mathrm{Zn} / \mathrm{RE}$ ratio and it could coexist with other secondary phases, like $\mathrm{W}$ phase, over a wide range of chemical compositions. Few studies are available [23-28] on the 
interaction between these two phases. Wang et al. [29] reported that the strengthening effect of $\mathrm{W}+\mathrm{LPSO}$ phase is greater than only LPSO in $\mathrm{Mg}-\mathrm{Zn}-\mathrm{Y}-\mathrm{Zr}$ alloys. These additional phases appear accompanied by LPSO structures in the Mg matrix and are frequently formed as precipitates in the as-cast state or as a result of thermal and/or thermomechanical processing of these alloys.

Researches on precipitation phenomena in Mg-TM-RE alloys have been mostly concentrated on nucleation, growth and distribution in the matrix for static precipitation [30-32] or during hot deformation process [33-38]. Specifically, dynamic precipitation of $\dot{\beta}$ precipitates has been reported by Hou et al. [38] during hot compression of $\mathrm{Mg}-8 \mathrm{Gd}-2 \mathrm{Y}-1 \mathrm{Nd}-0.3 \mathrm{Zn}-0.6 \mathrm{Zr}$ alloy who observed similar orientation relationships under static or dynamic precipitation. However, little data is available on the preferred alignment of precipitates. Analysis of the published literature indicates that precipitates are randomly distributed in the matrix [30-38]. In contrast, other authors report preferred alignment during the growth process [39-42]. Celotto et al. [40] observed continuous precipitates lying in the basal planes of a heat-treated AZ91alloy while Roostaei et al. [41] reported the formation of arrays of Gd-rich precipitates similar to W-phase, after a long heat treatment ( 240min) at $300{ }^{\circ} \mathrm{C}$ of GZ31 alloy. In a very recent publication, Deschamps et al. [42] have observed parallel bands of precipitates in the deformed Al-Cu-Li-Mg alloys. It is worth noting that, in the above studies no clear discussion has been made on the role of precipitates nucleation sites in the arrangement of precipitates.

In the current work, the formation of parallel arrays of precipitates in GZ41K alloy is studied and possible governing mechanisms are proposed. Using extensive SEM and TEM examinations, the role played by stacking faults present within the LPSO structures on the formation of preferential precipitation is demonstrated in the $\alpha-\mathrm{Mg}$ matrix. Finally the effect of strain rate on the volume fraction of precipitates is discussed. 


\section{Material and methods}

The GZ41K alloy with a nominal composition of $\mathrm{Mg}-3.5 \mathrm{Gd}-1 \mathrm{Zn}-0.6 \mathrm{Zr}$ (wt\%) was melted using pure $\mathrm{Mg}$, pure Zinc, $\mathrm{Mg}-10 \mathrm{Gd}$ and $\mathrm{Mg}-5 \mathrm{Zr}$ master alloys in an electric resistance furnace at $750^{\circ} \mathrm{C}$ under protection of $\mathrm{CO}_{2}$ atmosphere and then was poured at $715^{\circ} \mathrm{C}$ into a preheated steel mould. The as-cast material was homogenized in two steps, $2 \mathrm{hr}$ at $350^{\circ} \mathrm{C}$ followed by $10 \mathrm{hr}$ at $540^{\circ} \mathrm{C}$ and then extruded by an extrusion ratio of $8.5: 1$. The extruded rod, with the final diameter of $12 \mathrm{~mm}$, was used as the starting material in this study. Hot compression specimens $12 \mathrm{~mm}$ in height and $8 \mathrm{~mm}$ in diameter were machined from the as-extruded material and then subjected to solutionizing treatment at $540^{\circ} \mathrm{C}$ for $3 \mathrm{hr}$ followed by water quenching. Four thermal cycles were employed as shown in Fig. 1. After 5 min soaking at the temperatures of $450^{\circ} \mathrm{C}$, uniaxial hot compression cycles ((b) and (c) in Fig. 1) were conducted using a Zwick Rolling 250 testing machine. The test temperature was $450^{\circ} \mathrm{C}$, two strain rates of $10^{-3} \mathrm{~s}^{-1}$ and $10^{-1} \mathrm{~s}^{-1}$ were used and the specimens were immediately quenched after deformation to preserve the as-deformed high temperature microstructures. It should be mentioned that the compression direction was parallel to the extrusion direction. 


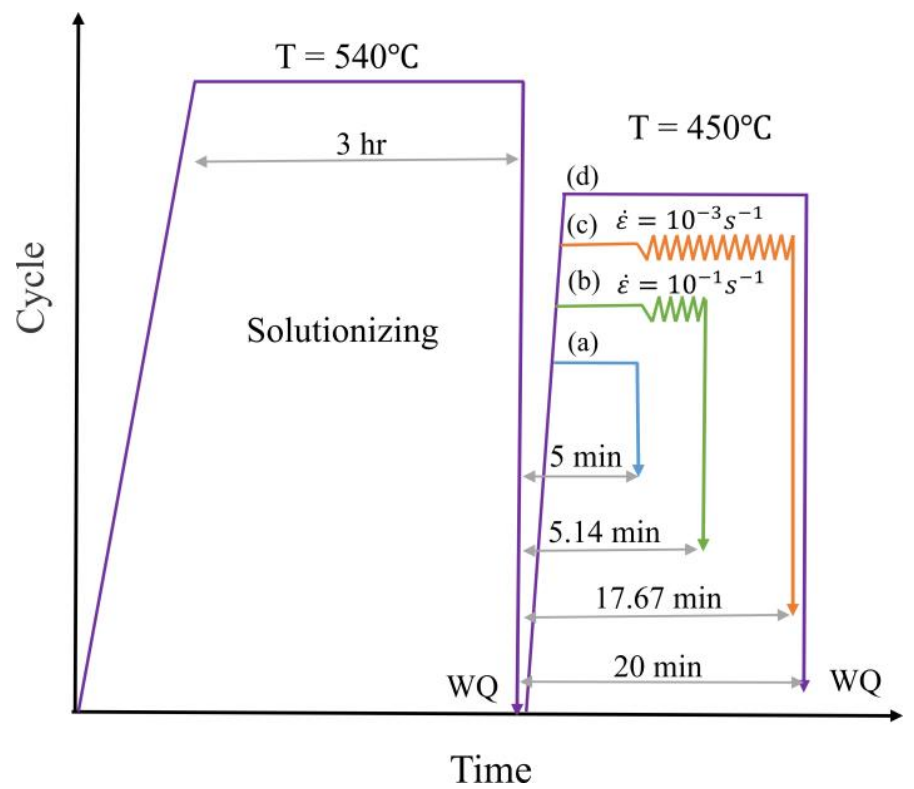

Fig. 1. The thermal/thermomechanical cycles used for the GZ41K alloy after solutionizing at $540^{\circ} \mathrm{C}$ for 3hr. Isothermal holding at $450^{\circ} \mathrm{C}$ for a) $5 \mathrm{~min}$ and d) $20 \mathrm{~min}$ and hot compressions at the strain rate of b)

$$
10^{-1} \mathrm{~s}^{-1} \text { and c) } 10^{-3} \mathrm{~s}^{-1} \text {. }
$$

In order to separate the effect of holding time on precipitation (static precipitation) from that of deformation on the formation of precipitates, two isothermal holding cycles were employed: 1) $450^{\circ} \mathrm{C}$ for $5 \mathrm{~min}$ (Fig.1a) equal to the soaking (holding) time before deformation; and 2) $20 \mathrm{~min}$ (Fig. 1d) holding time, which is almost equivalent to the sum of the soaking time before deformation and the compression time at the lowest strain rate $\left(10^{-3} \mathrm{~s}^{-1}\right)$. The as-Extruded and solutionized specimens were characterized by DTA analysis using heating and cooling rate of $5^{\circ} \mathrm{C} / \mathrm{min}$ to study the formation or dissolution of constituent phases. X-ray diffraction patterns of solutionized and hot deformed specimens were obtained using PANalytical X-ray diffractometer setup with $\mathrm{Cu} \mathrm{K}_{\alpha}$ radiation. For microstructural investigations, specimens were prepared by standard polishing procedures, initially with $\mathrm{SiC}$ abrasive papers and finally with $1 \mu \mathrm{m}$ alumina suspension. Specimens were chemically etched in 4\% Nital solution for 30s. LEXT OLS4100 laser confocal microscope for optical microscopy and Hitachi SU-8230 Field Emission-STEM for 
scanning electron microscopy were employed. Transmission electron microscopy investigation was performed using FEI Tecnai $\mathrm{G}^{2}$ Spirit BioTwin $120 \mathrm{kV}$ Cryo-TEM equipped with the highresolution TEM (HRTEM) and high-angle annular dark-field scanning transmission electron microscopy (HAADF-STEM). The specimen preparation for this purpose was completed via mechanical polishing followed by a precision ion polishing system (PIPS). Finally, volume fractions of precipitates were calculated by employing the ImageJ software.

\section{Results}

\subsection{Starting microstructure and thermal analysis}

The starting as-extruded microstructure of the alloy, as shown in Fig. 2a and 2b, consists of elongated grains in the extrusion direction accompanied by several types of particles: some large irregular-shape ones (denoted by I in Fig.2b) which are aligned in the extrusion direction as depicted by the yellow arrows in Fig. 2b; sparse large cubic particles dispersed in the matrix as enlarged and represented by II in Fig. 2c; and finally the smallest precipitates (denoted by III in Fig. 2b). It is worth noting that the orientations of these small particles depend on the orientation of $\alpha-\mathrm{Mg}$ grains and vary from one grain to another as can be seen in the matrix (Fig. 2.a). Microstructural features of the alloy after solutionizing at $540^{\circ} \mathrm{C}$ for $3 \mathrm{hr}$ are presented in Figs. 2c and 2 d. A comparison between Figs. $2 \mathrm{a}$ and $2 \mathrm{~b}$ with Figs. $2 \mathrm{c}$ and $2 \mathrm{~d}$ indicates that all the smallest

precipitates (type III) and irregular-shape particles (type I) have been dissolved in the $\alpha$-Mg matrix leaving it with some large cubic particles (type II) within the grains and at the grain boundaries. EDS analyses of particles in Fig. 2 listed in table 1, show that the $\mathrm{Zn} / \mathrm{Gd}$ ratio is almost identical for type I and type III particles. This indicates that while these particles have been formed at different steps during the processing, they have very similar compositions and thus dissolved in the matrix after homogenization. This dissolution can also be further confirmed by comparing $\mathrm{Zn}$ 
and Gd concentrations for both as-extruded and as-solutionized matrices in table 1. It can be seen that the amount of dissolved $\mathrm{Zn}$ and $\mathrm{Gd}$ in the matrix is increased as a result of alloy homogenization at $540^{\circ} \mathrm{C}$ for $3 \mathrm{hr}$.
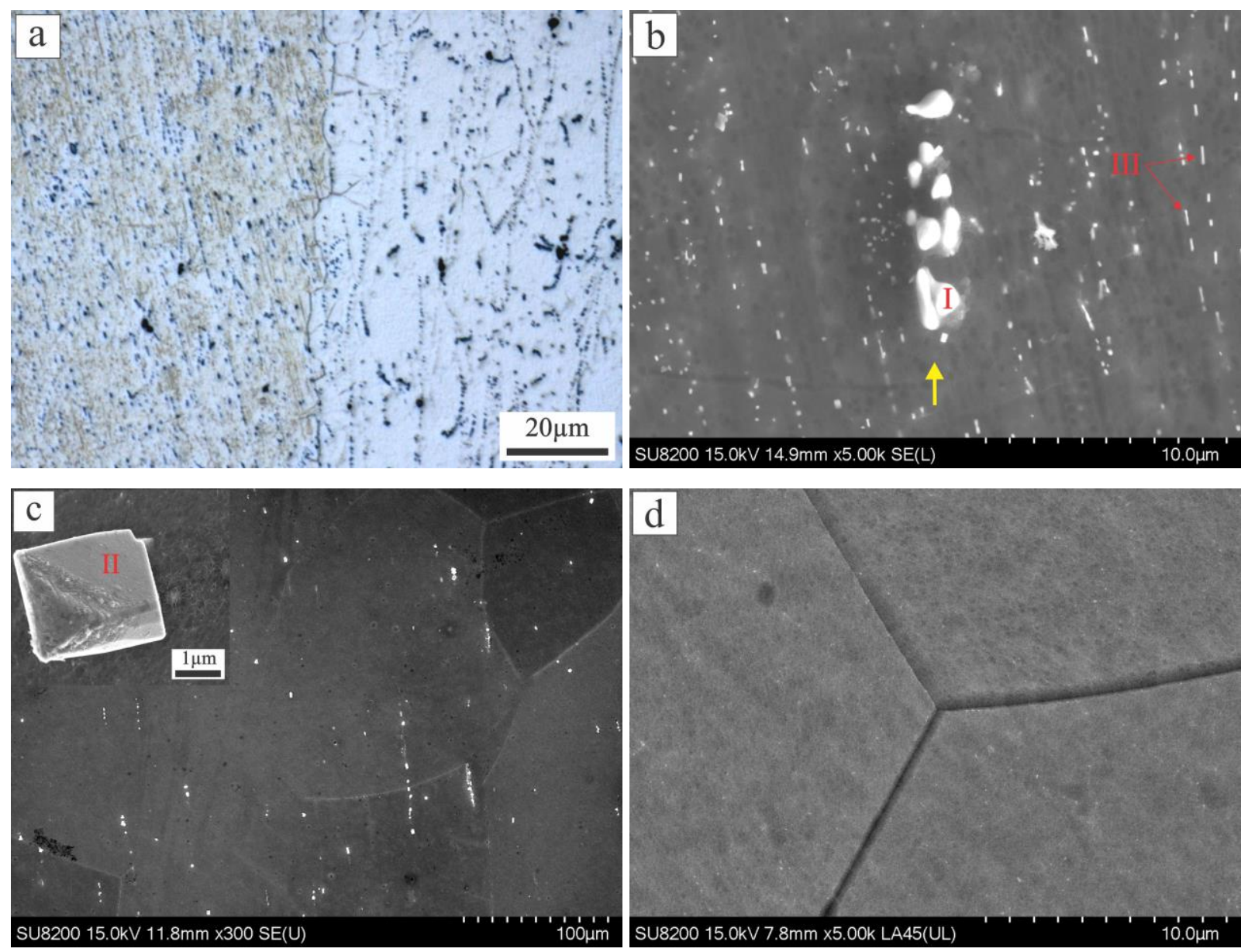

Fig. 2. Microstructure of GZ41 K alloy in a, b) as-extruded and c,d) as-solutionized at $540^{\circ} \mathrm{C}$ for $3 \mathrm{hr}$.

Table 1 EDS analysis of types I, II and III particles and also as-extruded, as-solutionized matrices in Fig. 2.

\begin{tabular}{cccccc}
\hline Spectrum & $\mathrm{Mg}(\mathrm{at} \%)$ & $\mathrm{Zn}(\mathrm{at} \%)$ & $\mathrm{Gd}(\mathrm{at} \%)$ & $\mathrm{Zr}(\mathrm{at} \%)$ & $\mathrm{Zn} / \mathrm{Gd}$ \\
\hline Type I & 61.03 & 25.96 & 13.01 & 0.00 & 2.00 \\
Type II & 20.37 & 0.91 & 78.52 & 0.20 & 86.29 \\
Type III & 89.64 & 7.06 & 3.30 & 0.00 & 2.14 \\
As-extruded matrix & 99.67 & 0.18 & 0.15 & 0.00 & --- \\
As-solutionized matrix & 98.35 & 0.95 & 0.69 & 0.01 & --- \\
\hline
\end{tabular}


DTA thermograms of as-extruded and as-solutionized conditions are depicted in Fig. 3. For the purpose of the DTA experiments, both specimens were heated to above the melting point followed by cooling to the room temperature. The main difference between the as-extruded (Fig. 3a) and as-solutionized (Fig. 3b) specimens is related to the heating cycle. During the heating cycle, a small endothermic peak appears at $519.2^{\circ} \mathrm{C}$ for the as extruded specimen (see inset graph in Fig.3a) which is due to the dissolution of both small and irregular particles in the as-extruded specimen, while no peak is observed for the solutionized specimen (inset graph in Fig.3b). This indicates that the precipitates present in the matrix have been dissolved and a supersaturated solid solution has been formed which is susceptible to form stable or metastable precipitates in the subsequent treatments. During cooling from the melt, exothermic peaks for both specimens have almost identical shapes and reveal that the formation temperatures for both type I and type III precipitates are in the $526^{\circ} \mathrm{C}$ and $506^{\circ} \mathrm{C}$ interval.
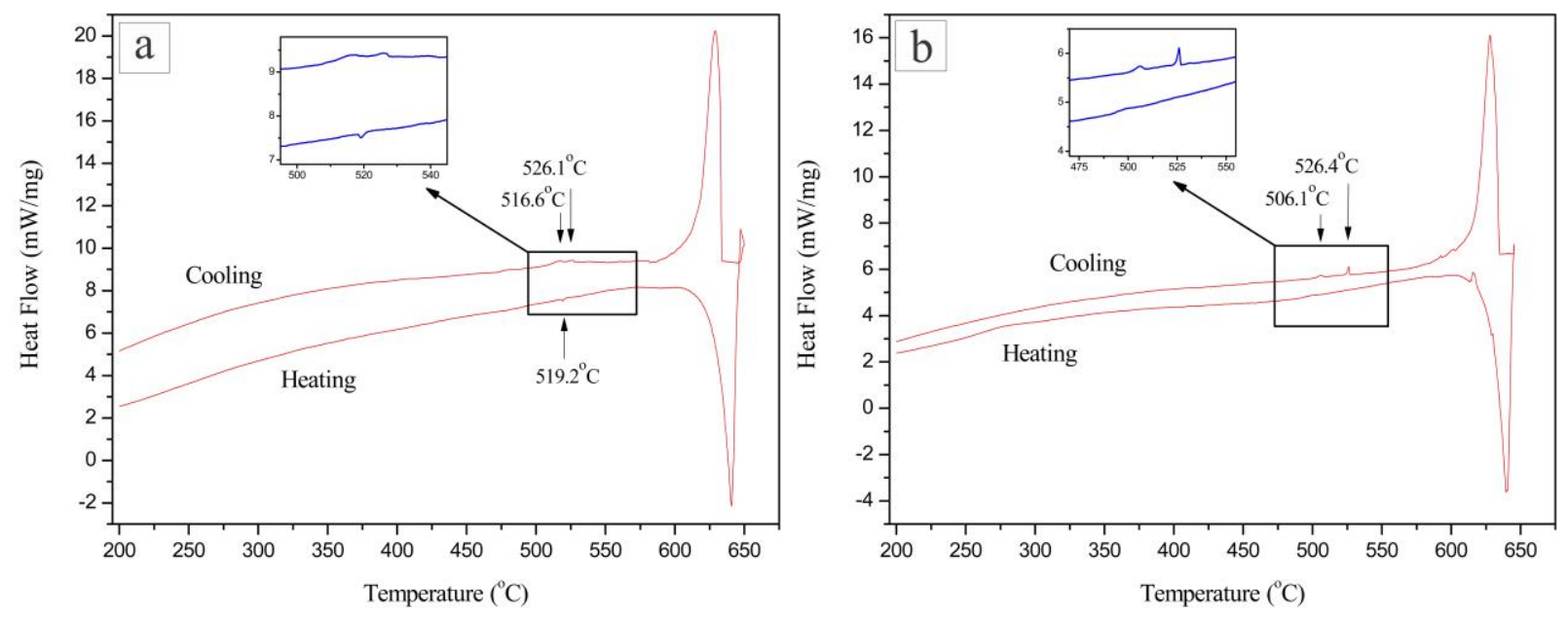

Fig. 3. Heating and cooling DTA thermograms of GZ41K alloy a) as-extruded and b) as-solutionized conditions.

\subsection{Hot compressed microstructures}

Microstructures of hot compressed alloy at $450^{\circ} \mathrm{C}$ and strain rates of $10^{-3} \mathrm{~s}^{-1}$ and $10^{-1} \mathrm{~s}^{-1}$ are shown in Fig. 4. Comparison between Figs. 4a and 4c indicates that the volume fraction of precipitates 
increased from $4 \%$ to $8 \%$ with increasing the strain rate from $10^{-3} \mathrm{~s}^{-1}$ to $10^{-1} \mathrm{~s}^{-1}$. For both strain rates, the precipitates are present in the grain interiors as well as at the grain boundaries. As can be seen in Figs. $4 \mathrm{~b}$ and $4 \mathrm{~d}$, most of the interior precipitates are aligned in parallel arrays. These sets of arrays are not fully straight and are bent in some regions (Figs. 4a and 4c) and appear to follow the local strain fields. Also, comparing the SEM micrographs in Figs. 4b and 4d indicates that the orientation of precipitates in each array is more irregular at the higher strain rate, further supporting the influence of the strain rate on precipitation orientation.
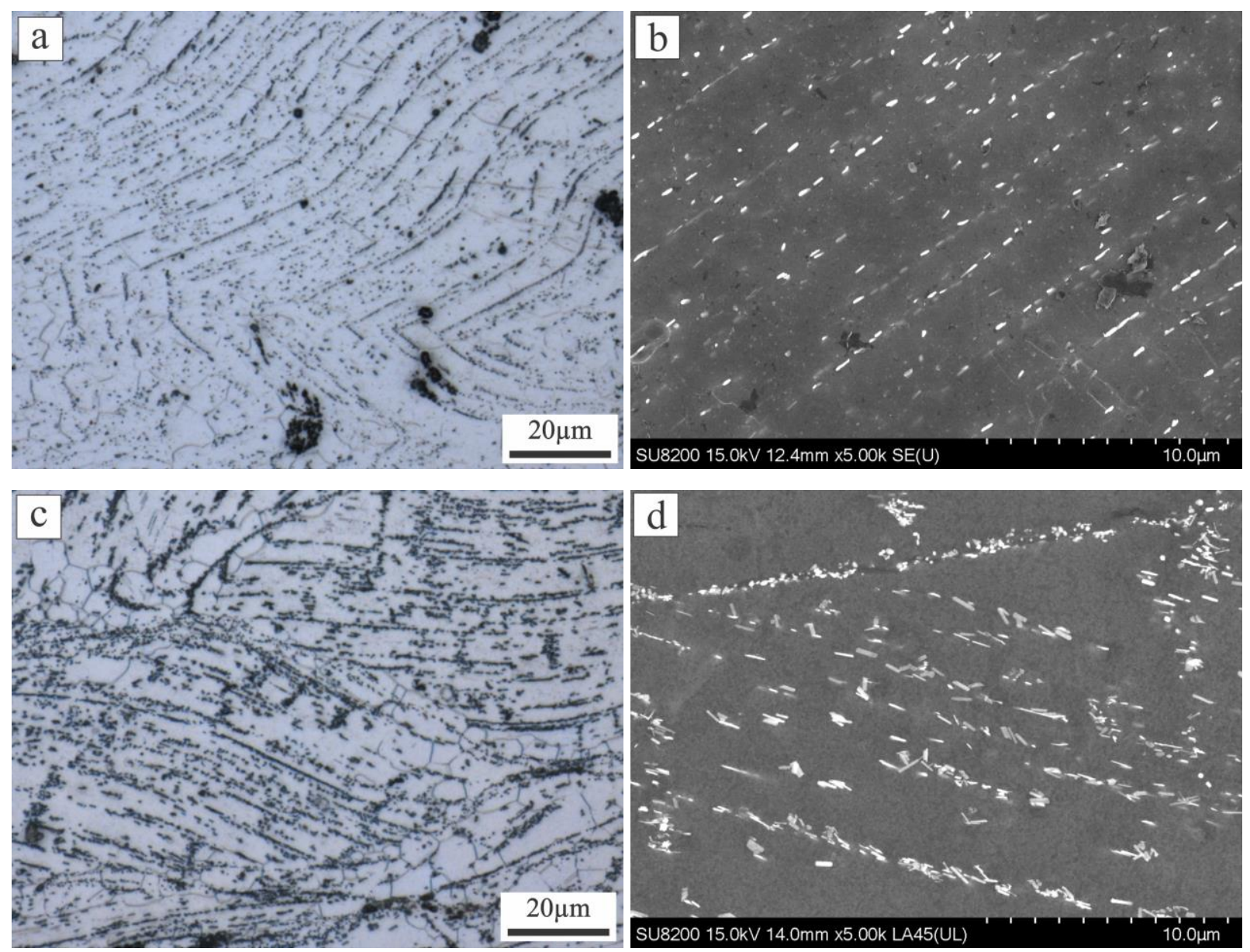

Fig. 4. Microstructure of hot compressed GZ41K alloy at $450^{\circ} \mathrm{C}$ at strain rates of a, b) $10^{-3} \mathrm{~s}^{-1}$ and c, d) $10^{-}$ ${ }^{1} \mathrm{~S}^{-1}$.

As shown in the TEM micrographs of the specimen deformed at the strain rate of $10^{-3} \mathrm{~s}^{-1}$, microstructure contains a large amount of stacking faults (black arrows in Figs. 5a and 5b) and 
also coincidence of SFs and slip bands (white arrows in Fig. 5b). In both cases, the precipitates are laid along these parallel structural defects. Furthermore, there are some dislocations crossing these SFs and slip bands as indicated circles in Fig. 5b. The HAADF-STEM image of the Fig.5a is presented in Fig. 6a showing those stacking faults as white lines. Atomic weights of $\mathrm{Gd}, \mathrm{Zn}$ and $\mathrm{Zr}$ solute elements are all higher than that of $\mathrm{Mg}$ and thus wherever the concentration of solute elements is higher than that of the matrix, the HAADF-STEM image will be brighter. Therefore, it can be concluded that these elements are more likely to segregate to the SFs rather than having a uniform distribution in the matrix. HRTEM observation of the SFs in Fig. 5a revealed that these stacking faults belong to a 14H-LPSO structure, i.e. separated from each other by 14 stacking layers. Consequently, the precipitates have nucleated on 14H-LPSO structures.
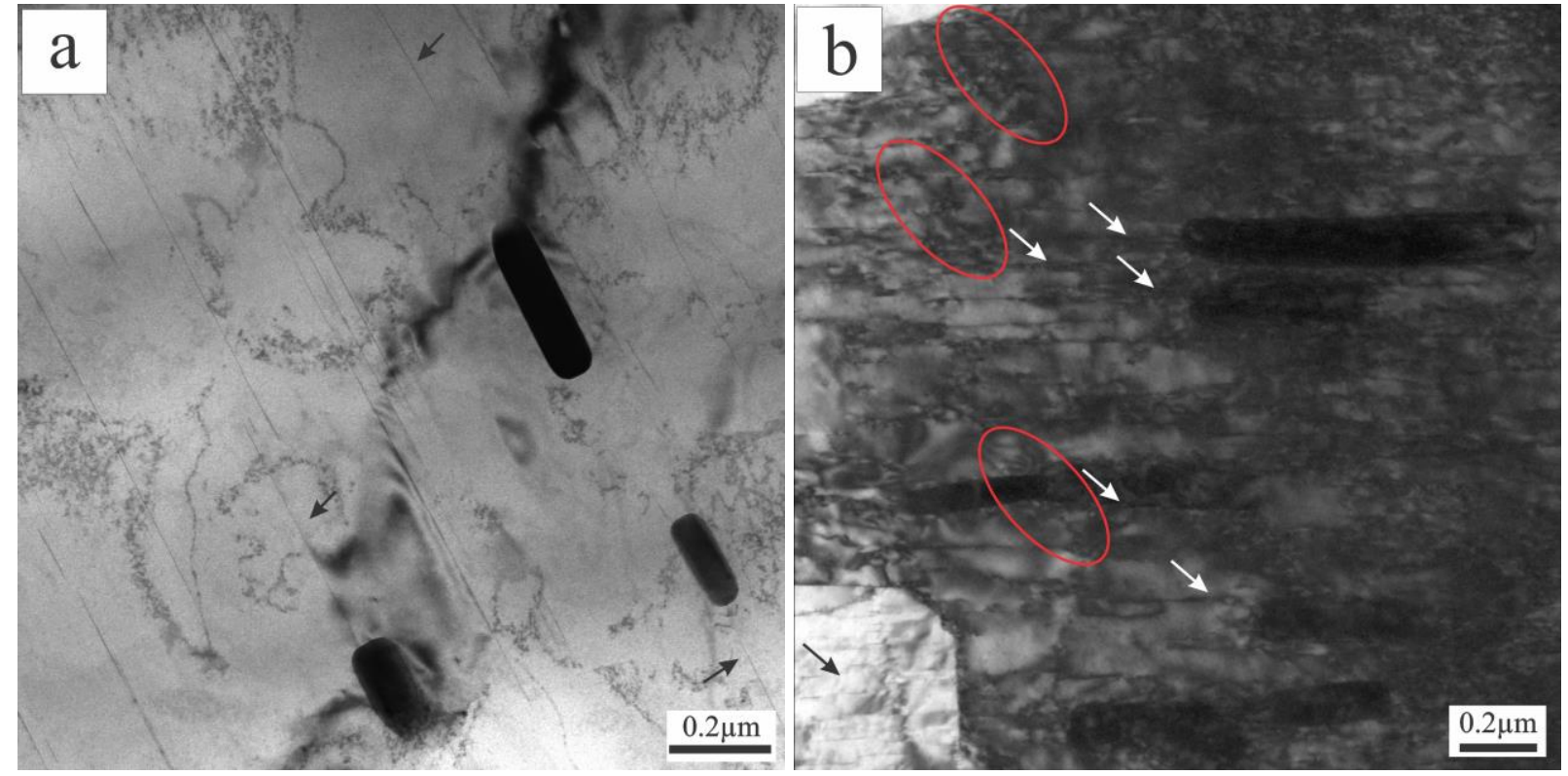

Fig. 5. TEM images of the specimen deformed at the strain rate of $10^{-3} \mathrm{~s}^{-1}$ showing precipitates lying on a) stacking faults (black arrows) of LPSO structure and b) slip bands (white arrows) in a non-recrystallized grain. Intersection between dislocations and slip bands are circled in Fig. 5.b. 


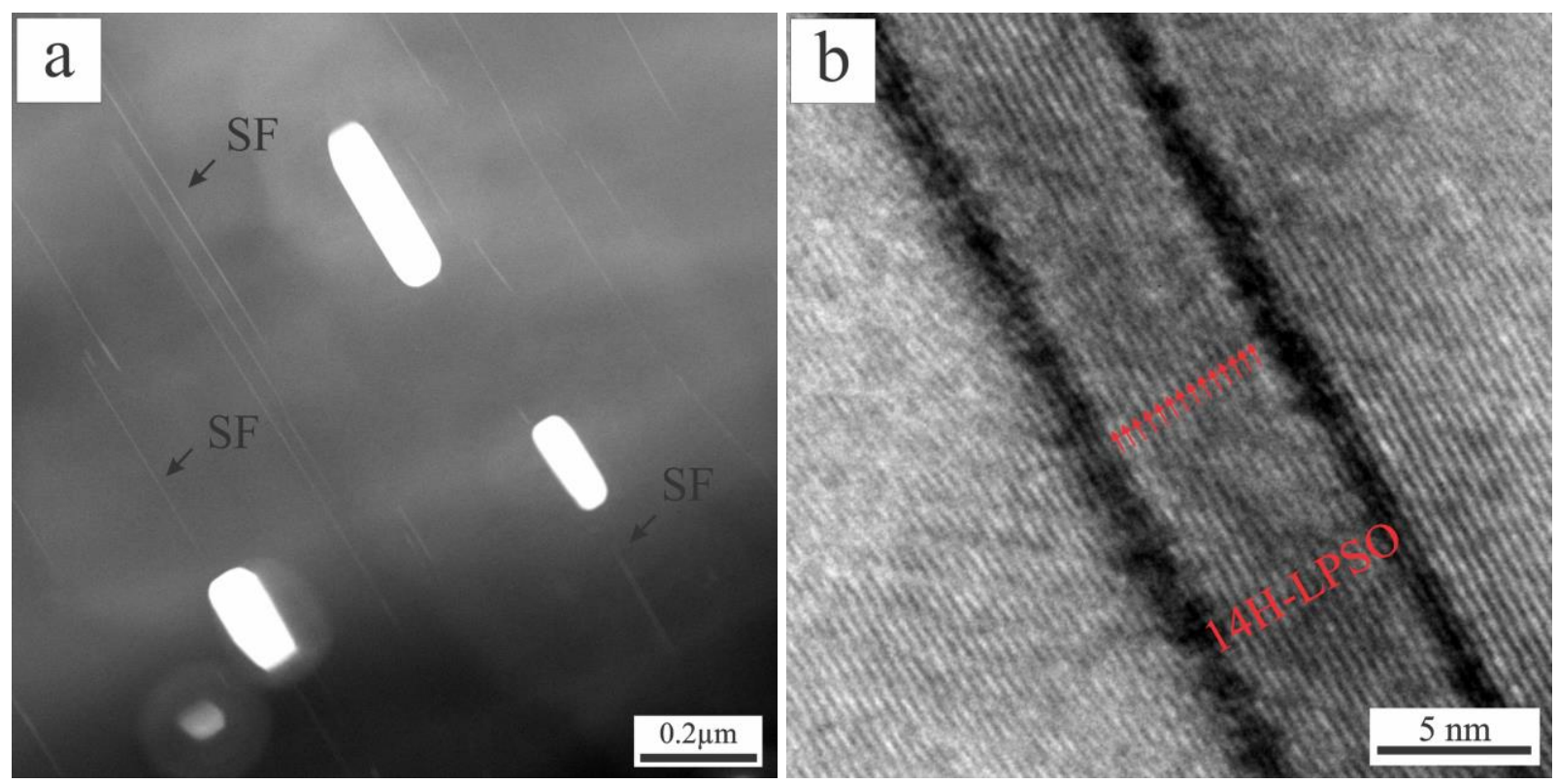

Fig. 6. a) HAADF-STEM image of the micrograph in Fig.5.a revealing segregated solute elements on stacking faults and b) HRTEM image in which arrows denote the 14 atomic layers of the 14H-LPSO structure.

Chemical composition of the precipitates formed during deformation was determined by comparing X-ray diffraction patterns of as-solutionized and as-deformed (hot compressed at the strain rate of $10^{-3} \mathrm{~s}^{-1}$ ) specimens. The presence of some extra characteristic peaks can be observed in the diffraction patterns of the as-deformed specimen which assigned by rhombic in Fig. 7. Phase peaks can be related to type I and III precipitates based on microstructural observations (comparison of Figs. 2c and 2d with Figs. 4a and 4c). Determining the exact composition of this phase with a similar composition to W-phase in Mg-Zn-Y alloys have been a controversial subject and several compositions such as $\mathrm{W}$-phase $\left(\mathrm{Mg}_{3} \mathrm{Zn}_{3} \mathrm{Gd}_{2}\right)$ [43], $\mathrm{Mg}_{5} \mathrm{Gd}$ phase $[11,41,44]$ or a combination of those have been assigned to this set of peaks. However, TEM investigations [12, $16,45-48]$ revealed that this phase is a $(\mathrm{Mg}, \mathrm{Zn})_{3} \mathrm{Gd}$ phase with FCC structure similar to $\mathrm{Mg}_{3} \mathrm{Gd}$ phase. 


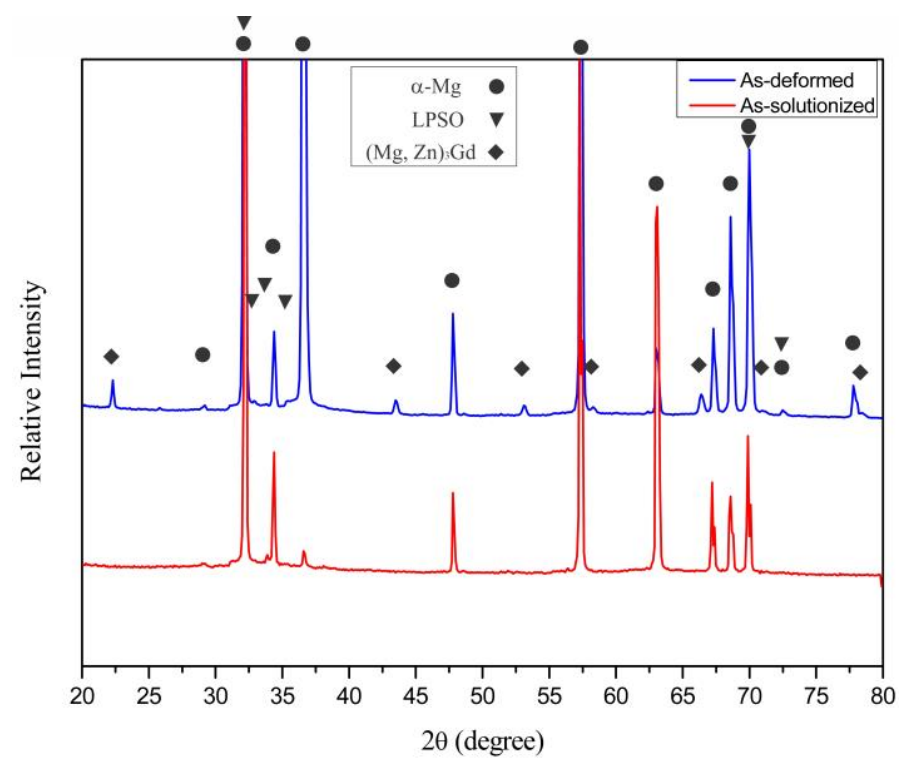

Fig. 7. X-ray diffraction patterns of GZ41K alloy in the as-solutionized state and as-deformation at $450^{\circ} \mathrm{C}$ and strain rate of $10^{-3} \mathrm{~s}^{-1}$.

\subsection{Isothermal holding microstructure}

After isothermal holding of the as-solutionized alloys for $5 \mathrm{~min}$ at $450^{\circ} \mathrm{C}$ followed by water quenching (Figs. 8a and 8b), no new precipitates were detected neither in the matrix nor at the grain boundaries or twin boundaries. However, in the case of specimens hold for $20 \mathrm{~min}$, as illustrated in Figs. 8c and 8d, precipitates are present at the grain and twin boundaries as well as inside the grains. In some grains, the intragranular precipitates are arranged in parallel arrays, as evidenced in Fig 8c. Also, precipitation orientation in each array has changed when twins are present in the matrix (Fig. 8d). The volume fraction of precipitates at this condition (i.e. 20 min isotheral holding) was measured to about $2 \%$ which is well below those measured for hot deformed specimens $(4 \%$ to $8 \%)$. The above results indicate that the strain-induced precipitation is responsible for the higher volume fractions of precipitates after hot compression at $450^{\circ} \mathrm{C}$. 

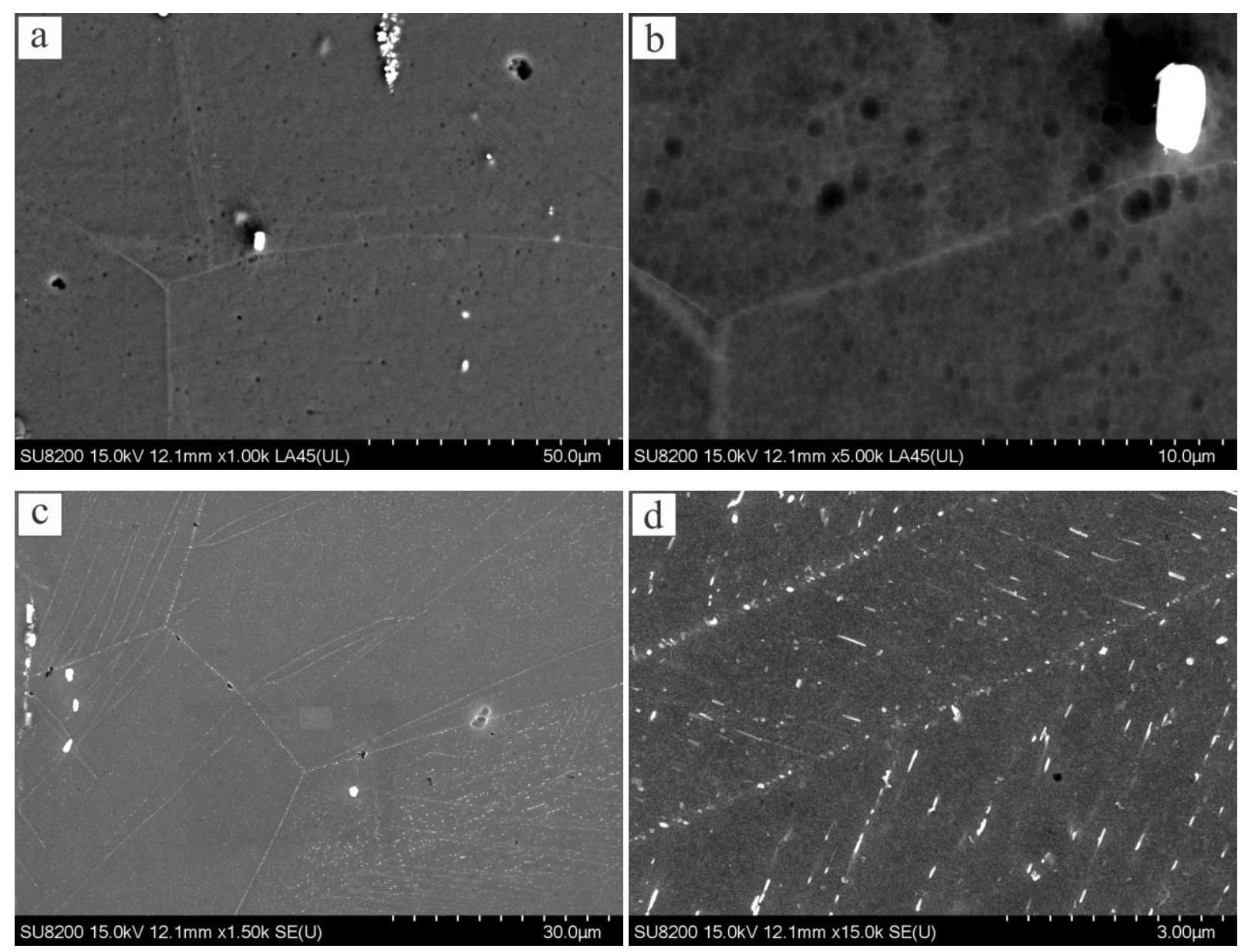

Fig. 8. SEM images of the microstructure after isothermal holding at $450^{\circ} \mathrm{C}$ a,b) 5 min holding, showing the precipitate-free grain interior and grain boundaries; c,d) 20 min holding, contains precipitates inside the grains and twins as well as at grain boundaries and twin boundaries. ( $b$ and $d$ are higher magnification images of a and c, respectively).

\subsection{Solute element distribution}

Figs. 9 and 10 present SEM and EDS analyses after deformation at $450^{\circ} \mathrm{C}$ and strain rates of $10^{-3}$ $\mathrm{s}^{-1}$ and $10^{-1} \mathrm{~s}^{-1}$, respectively. Mapping and line scan analyses showed that, for both deformation conditions, precipitate arrays are enriched in $\mathrm{Zn}, \mathrm{Gd}$ and $\mathrm{Zr}$. However, comparison between elemental maps in Figs. 9 and 10 indicates that the concentration of solute atoms in the matrix at the strain rate of $10^{-3} \mathrm{~s}^{-1}$, is less than those for the specimen tested at the strain rate of $10^{-1} \mathrm{~s}^{-1}$. This 
can be attributed to the longer time for the formation of precipitates at lower strain rates via diffusion of solute elements. In contrast, a uniform distribution of solute elements was observed between arrays of precipitates as reported in Figs. 9 and 10. Finally, it was also found that precipitates are more aligned after deformation at the strain rate of $10^{-3} \mathrm{~s}^{-1}$ (Fig. 9) than those for the strain rate of $10^{-1} \mathrm{~s}^{-1}$ (Fig. 10).
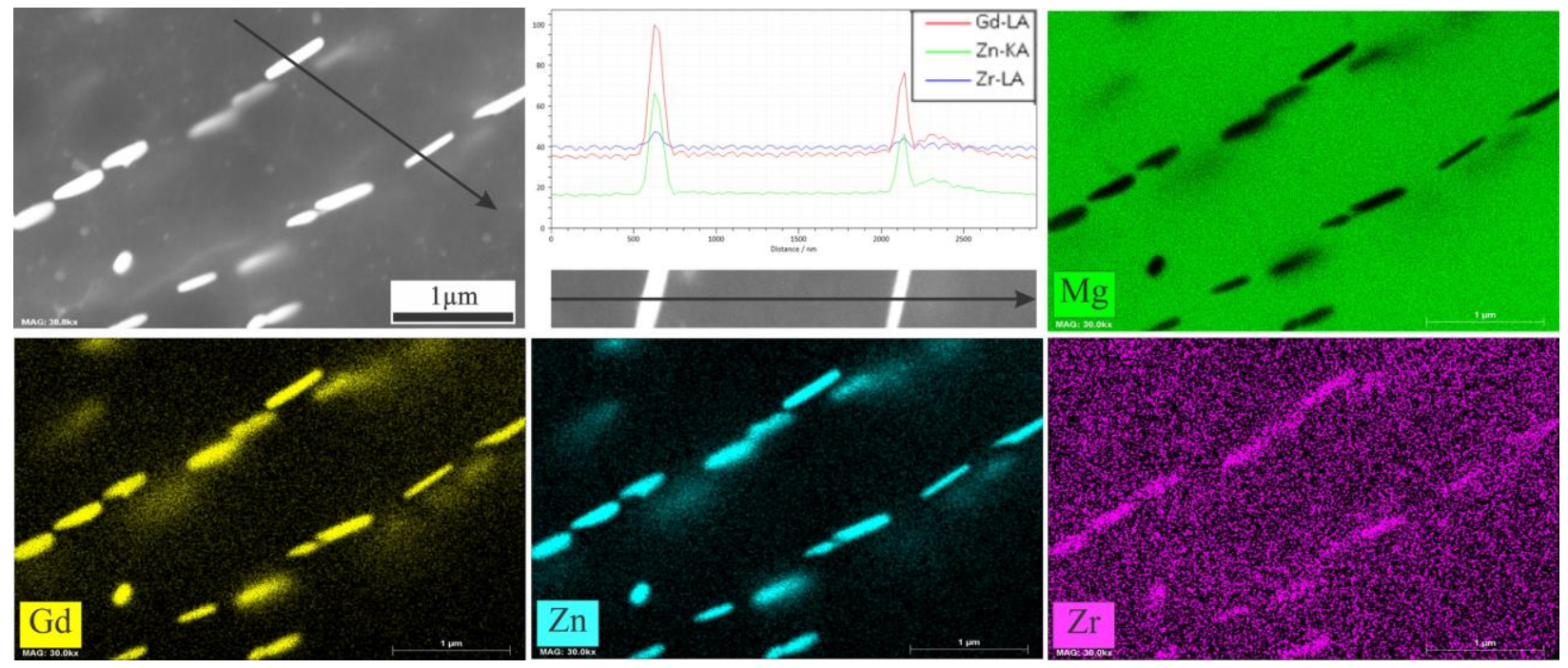

Fig. 9. SEM image and EDS analyses of precipitates in GZ41K alloy deformed at $450{ }^{\circ} \mathrm{C}$ and strain rate of $10^{-3} \mathrm{~s}^{-1}$.
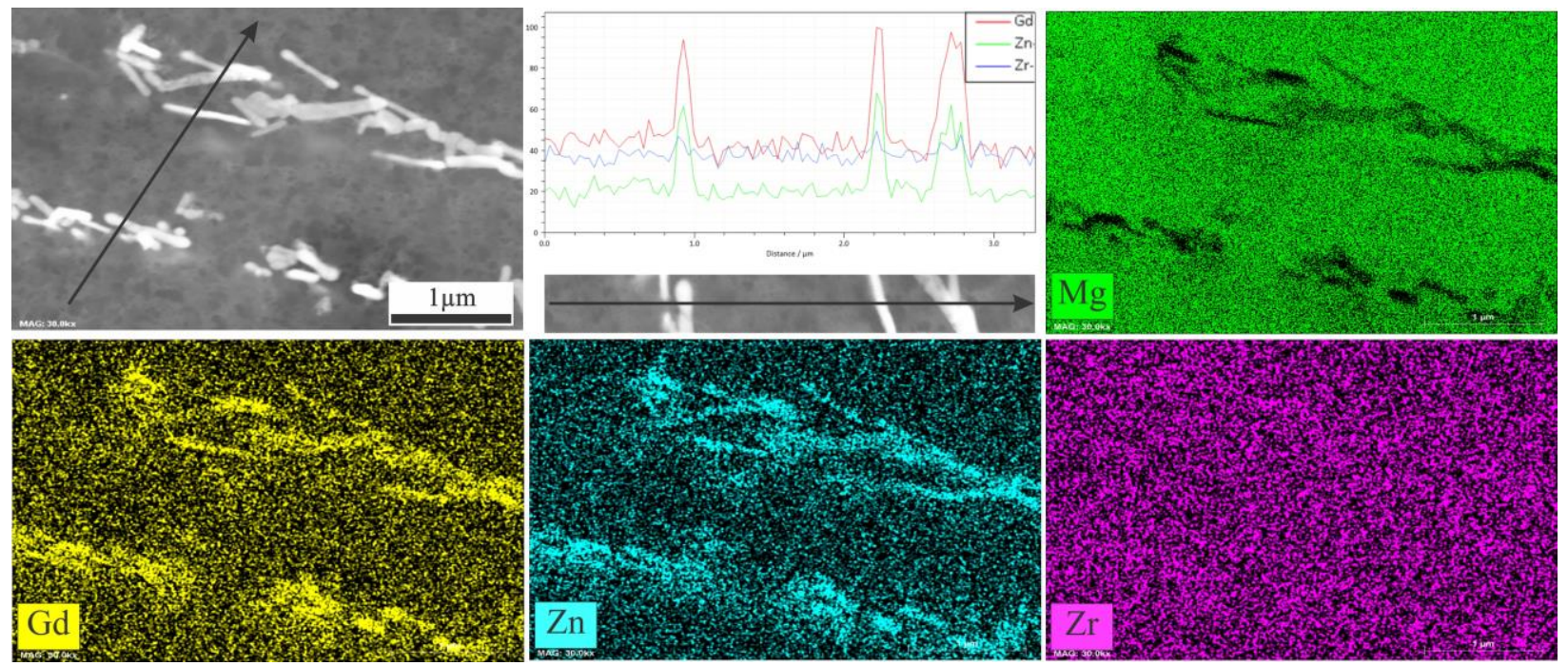

Fig. 10. SEM image and EDS analyses of precipitates in GZ41K alloy deformed at $450{ }^{\circ} \mathrm{C}$ and strain rate of $10^{-1} \mathrm{~s}^{-1}$. 


\section{Discussion}

\section{Mechanisms of precipitate formation in parallel arrays}

The formation of parallel arrays of precipitates after isothermal holding has been reported previously [39-41] and also revealed in the present investigation. However, to the knowledge of the authors, no or very little work has been reported on the governing mechanisms. In the present investigation, on the basis of some simplifying assumptions, a combination of three possible mechanisms is proposed to account for the occurrence of the observed precipitation phenomenon. Specifically, these are precipitation on certain sets of planes, precipitation on slip bands and precipitation on the stacking faults of LPSO structures.

Static or dynamic precipitation in the GZ41K alloy, as illustrated in Figs. $8 \mathrm{~b}$ and $4 \mathrm{~b}$, respectively results in the formation of $(\mathrm{Mg}, \mathrm{Zn})_{3} \mathrm{Gd}$ rod-like particles which are oriented mostly parallel to each other. This was also described before for the as-extruded microstructure, Fig. 2a, in which the orientation of these parallel arrays of precipitates changed from one grain to another. Published literature on RE-containing magnesium alloys $[38,46,49]$ have shown that, precipitates nucleate and grow on definite crystallographic planes of the $\alpha$-Mg matrix. However, Analysis of the published data revealed that although these precipitates imitate a certain $\alpha-\mathrm{Mg}$ matrix crystallographic orientation, their nucleation had taken place on random sites rather than in the form of continuous arrays. Therefore, the orientation relationship is not the only parameter which could solely explain the formation of these parallel arrays.

Fig. $5 \mathrm{~b}$ shows the nucleation and growth of the precipitates on parallel bands inside the grains. The latter are slip bands most probably from the movement of the basal planes in the Mg HCP structure.

Precipitation on slip bands has also been reported by Choudhuri et al. [39] for a Ti-Mo-Nb-Al alloy and have been related to a dynamic precipitation process during hot tensile test. It is worth 
noting that no data is available on precipitation on slip bands in $\mathrm{Mg}-\mathrm{RE}$ or actually any other $\mathrm{Mg}$ based alloys. Detailed analysis of the hot deformed microstructures of the hot deformed samples revealed that the precipitate arrays were either bent in some regions especially near initial grain boundaries or arranged in zigzag shape in the interiors of grains as illustrated in Figs. 4a and 4c. However, it is well-known that slip bands are mostly parallel straight lines and cannot bend or become zigzag in the same grain, similar to what could be observed in Fig. 4. The formation of bent or zigzag kinking of precipitate bands has been reported by Oñorbe et al. [50] and Yamasaki et al. [51] for long period stacking ordered (LPSO) structures in Mg-TM-RE alloys. On the basis of obtained results in the present investigation, it can be said that, LPSO structures are present in the matrix and the arrays of precipitates nucleated on stacking faults of the LPSO structure as it is observed in Figs. 5a and 6a for the hot deformed microstructure. Furthermore, as illustrated in Fig $8 \mathrm{~d}$, precipitates also formed in parallel arrays during $20 \mathrm{~min}$ isothermal holding at $450^{\circ} \mathrm{C}$ on nondeformed samples, i.e. in the absence of slip bands. Therefore, it can be concluded that this precipitates were also formed on LPSO structures. Nevertheless, it is necessary to discuss why and how $(\mathrm{Mg}, \mathrm{Zn})_{3} \mathrm{Gd}$ precipitates could form on the LPSO structures?

During solutionizing treatment, $(\mathrm{Mg}, \mathrm{Zn})_{3} \mathrm{Gd}$ precipitates dissolve in the $\alpha-\mathrm{Mg}$ matrix (Fig. 2c), but as shown in Fig. 6a, the distribution of solute elements is not uniform and as reported by Wu et al. [52] dissolution of $(\mathrm{Mg}, \mathrm{Zn})_{3} \mathrm{Gd}$ particles during solutionizing resulted in the growth of lamellar 14H-LPSO structure. Also, according to the observations of Zheng et al. [53] and Yamasaki et al. [54] the solute elements prefer to segregate into SFs of LPSO structure and lead to the growth of the LPSO structure in both longitudinal and transverse directions. DTA analysis in Fig. 3 revealed that $519.2^{\circ} \mathrm{C}$ is very close to the critical temperature below which the $(\mathrm{Mg}, \mathrm{Zn})_{3} \mathrm{Gd}$ phase would be stable. Therefore, from a thermodynamic point of view, holding a supersaturated solid solution 
alloy below $519.2^{\circ} \mathrm{C}\left(450^{\circ} \mathrm{C}\right.$ in this study) could result in the precipitation of $(\mathrm{Mg}, \mathrm{Zn})_{3} \mathrm{Gd}$ phase. The presence of precipitates in parallel arrays after 20 min holding at $450^{\circ} \mathrm{C}$ in the undeformed sample (Figs. 8c and 8d) reveals that, from a kinetic point of view, such holding time is sufficient for the nucleation of these precipitates.

According to the above discussions, the LPSO structures that are formed during the solutionizing treatment are likely to decompose to $(\mathrm{Mg}, \mathrm{Zn})_{3} \mathrm{Gd}$ precipitates and individual $\mathrm{SFs}$ at $450^{\circ} \mathrm{C}$ because of lattice contractions and thermodynamic stability at $450^{\circ} \mathrm{C}$. However, this decomposition is only partial as the LPSO structures, SFs and $(\mathrm{Mg}, \mathrm{Zn})_{3} \mathrm{Gd}$ phase are all present at a given temperature [54]. Consequently, the formation of the precipitate arrays during $20 \mathrm{~min}$ isothermal holding (Fig. 8d) could be attributed to the nucleation of $(\mathrm{Mg}, \mathrm{Zn})_{3} \mathrm{Gd}$ particles on pre-existing SFs and also the SFs remained from LPSO decomposition.

Deformation at high temperatures activates some of the non-basal slip systems and therefore dislocation intersections with LPSO structures will be increased as for example circled in Fig. $5 \mathrm{~b}$. Similar findings have also been reported by Hu et al. [55] who observed a Cottrell atmosphere of solute elements at the intersection of dislocations and SFs of LPSO structure [55] and related it to the role played by lattice defects as favorable sites for accommodation of the elastic strains around large solute atoms. Consequently, the combination of solute enriched regions inside LPSO structures and the segregation of solute elements to the LPSO structure plus the presence of parallel arrays formed by SFs on the LPSO structure create favorable conditions for dynamic precipitation of $(\mathrm{Mg}, \mathrm{Zn})_{3} \mathrm{Gd}$.

Furthermore, compressive deformation will result in lattice contraction in both a and c directions of HCP structure [56] and thus SFs, which are highly sensitive to lattice expansion and contraction [19], become unstable[57]. As a result, the $\mathrm{L}_{2}$ structure arrangement of solute elements on the 
unstable SFs should be decomposed and the elements will diffuse out of the SFs and dissolve into the $\alpha-\mathrm{Mg}$ matrix. Dissolution of precipitates increases the excess energy of the system and makes the system unstable since the matrix become supersaturated [58]. Under these conditions, formation of precipitates would be a suitable choice for the system to reduce its internal energy.

It's well established that under the static precipitation from a uniform supersaturated solid solution, solute elements diffuse toward the newly formed precipitates and form a solute depleted region around precipitates as well as a solute-rich zone in the interparticle regions [59]. Uniform distribution of solute in the matrix and adjacent to the particle/matrix interface (Figs. 9 and 10) suggests that before the precipitation process, solute elements had been segregated to some preferable sites which are the SFs of the LPSO structures and specially SF/dislocation intersections. Therefore, diffusion of solute elements across the stacking faults of the LPSO structure is probably responsible for the formation of $(\mathrm{Mg}, \mathrm{Zn})_{3} \mathrm{Gd}$ precipitates on SF-dislocation intersections.

Comparison of Figs. $4 \mathrm{a}$ and $4 \mathrm{c}$, indicates that the precipitation is influenced by deformation rate and the volume fraction of deformation-induced precipitation (DIP) at the strain rate of $10^{-1} \mathrm{~s}^{-1}$ is higher than $10^{-3} \mathrm{~s}^{-1}$ at $450^{\circ} \mathrm{C}$. Fundamentally, DIP takes place under the conditions that deformation promotes the movement of atoms in order to form precipitates and also provides additional sites for precipitation, similar to dislocation intersections [49] or deformation-induced vacancies [60]. Dislocation density is lower at low strain rates and elevated temperatures owing to the high dislocation annihilation and ease of dynamic recovery. The dislocation density increases strain rate according to the following equation, adapted from McCormick [61]:

$\dot{\varepsilon}=\rho\left[\frac{4 \mathrm{bC}_{\mathrm{v}} \mathrm{D}_{0}}{\mathrm{l}} \exp \left(-\mathrm{Q}_{\mathrm{m}} / \mathrm{KT}\right)\right]$ 
where $\rho, C_{v}, D_{0}, b, Q_{m}$ and 1 are dislocation density, vacancy concentration, diffusion frequency factor, burger's vector, solute migration activation energy and effective radius of solute atmosphere around a dislocation, respectively. The interactions and junctions between dislocations, especially at enhanced strain rates, promotes precipitation nucleation and growth [62]. Therefore, intersections between SFs and dislocations increases with dislocation density resulting in increased potential for precipitation under higher strain rate conditions.

\section{Conclusions}

Formation of precipitate arrays during hot compression of GZ41K magnesium alloy and the effect of strain rate on the deformation-induced precipitation were investigated in the current work. The main findings of this study are as follows:

1- Some large and small $(\mathrm{Mg}, \mathrm{Zn})_{3} \mathrm{Gd}$ particles were identified in as-extruded GZ41K alloy. The formation temperature of these particles is in the $506^{\circ} \mathrm{C}$ to $526^{\circ} \mathrm{C}$ range.

2- Static precipitation of $(\mathrm{Mg}, \mathrm{Zn})_{3} \mathrm{Gd}$ particles was observed on the individual SFs as well as on LPSO structures and only in sample held for $20 \mathrm{~min}$ at $450^{\circ} \mathrm{C}$.

3- Applying hot compression, leads to dynamic decomposition of LPSO structures and formation of precipitates in parallel continuous arrays. The precipitate volume fraction doubled with increasing the strain rate from $10^{-3} \mathrm{~s}^{-1}$ to $10^{-1} \mathrm{~s}^{-1}$.

4- A combination of precipitation on specific planes, precipitation on the stacking faults of the LPSO structures, and precipitation on slip bands were observed and possible governing mechanism based on dislocation intersections is proposed.

\section{References}


[1] N.K. T HOMMA, S. KAMADO, Fabrication of extraordinary high-strength magnesium alloy by hot extrusion, Scripta Materialia, 61 (2009) 644-647.

[2] I.A. Yakubtsov, B.J. Diak, C.A. Sager, B. Bhattacharya, W.D. MacDonald, M. Niewczas, Effects of heat treatment on microstructure and tensile deformation of Mg AZ80 alloy at room temperature, Materials Science and Engineering: A, 496 (2008) 247-255.

[3] N. Afrin, D.L. Chen, X. Cao, M. Jahazi, Strain hardening behavior of a friction stir welded magnesium alloy, Scripta Materialia, 57 (2007) 1004-1007.

[4] L. Zheng, H. Nie, W. Liang, H. Wang, Y. Wang, Effect of pre-homogenizing treatment on microstructure and mechanical properties of hot-rolled AZ91 magnesium alloys, Journal of Magnesium and Alloys, 4 (2016) 115-122.

[5] C. Chen, J. Chen, H. Yan, B. Su, M. Song, S. Zhu, Dynamic precipitation, microstructure and mechanical properties of $\mathrm{Mg}-5 \mathrm{Zn}-1 \mathrm{Mn}$ alloy sheets prepared by high strain-rate rolling, Materials \& Design, 100 (2016) 58-66.

[6] D.H. Bae, S.H. Kim, D.H. Kim, W.T. Kim, Deformation behavior of Mg-Zn-Y alloys reinforced by icosahedral quasicrystalline particles, Acta Materialia, 50 (2002) 2343-2356.

[7] J. Gröbner, A. Kozlov, X.-Y. Fang, S. Zhu, J.-F. Nie, M.A. Gibson, R. Schmid-Fetzer, Phase equilibria and transformations in ternary Mg-Gd-Zn alloys, Acta Materialia, 90 (2015) 400-416.

[8] J.-K. Kim, W.-S. Ko, S. Sandlöbes, M. Heidelmann, B. Grabowski, D. Raabe, The role of metastable LPSO building block clusters in phase transformations of an Mg-Y-Zn alloy, Acta Materialia, 112 (2016) 171-183.

[9] J.F. Nie, K. Oh-ishi, X. Gao, K. Hono, Solute segregation and precipitation in a creep-resistant Mg-GdZn alloy, Acta Materialia, 56 (2008) 6061-6076.

[10] F. Lu, A. Ma, J. Jiang, D. Yang, Q. Zhou, Review on long-period stacking-ordered structures in Mg-ZnRE alloys, Rare Metals, 31 (2012) 303-310.

[11] F.M. Lu, A.B. Ma, J.H. Jiang, D.H. Yang, Y.C. Yuan, L.Y. Zhang, Formation of profuse long period stacking ordered microcells in Mg-Gd-Zn-Zr alloy during multipass ECAP process, Journal of Alloys and Compounds, 601 (2014) 140-145.

[12] J. Zhang, W. Zhang, L. Bian, W. Cheng, X. Niu, C. Xu, S. Wu, Study of Mg-Gd-Zn-Zr alloys with long period stacking ordered structures, Materials Science and Engineering: A, 585 (2013) 268-276.

[13] C. Xu, M.Y. Zheng, K. Wu, E.D. Wang, G.H. Fan, S.W. Xu, S. Kamado, X.D. Liu, G.J. Wang, X.Y. Lv, Influence of rolling temperature on the microstructure and mechanical properties of $\mathrm{Mg}-\mathrm{Gd}-\mathrm{Y}-\mathrm{Zn}-\mathrm{Zr}$ alloy sheets, Materials Science and Engineering: A, 559 (2013) 615-622.

[14] X. Zhang, L. Meng, C. Fang, P. Peng, F. Ja, H. Hao, Effect of Nd on the microstructure and mechanical properties of Mg-8Gd-5Y-2Zn-0.5Zr alloy, Materials Science and Engineering: A, 586 (2013) 19-24.

[15] S. Huang, J. Wang, F. Hou, X. Huang, F. Pan, Effect of Gd and Y contents on the microstructural evolution of long period stacking ordered phase and the corresponding mechanical properties in $\mathrm{Mg}-$ Gd-Y-Zn-Mn alloys, Materials Science and Engineering: A, 612 (2014) 363-370.

[16] W.J. Ding, Y.J. Wu, L.M. Peng, X.Q. Zeng, G.Y. Yuan, D.L. Lin, Formation of 14H-type long period stacking ordered structure in the as-cast and solid solution treated Mg-Gd-Zn-Zr alloys, Journal of Materials Research, 24 (2011) 1842-1854.

[17] Y.J. Wu, D.L. Lin, X.Q. Zeng, L.M. Peng, W.J. Ding, Formation of a lamellar 14H-type long period stacking ordered structure in an as-cast Mg-Gd-Zn-Zr alloy, Journal of Materials Science, 44 (2009) 1607-1612.

[18] J. Yang, L. Wang, L. Wang, H. Zhang, Microstructures and mechanical properties of the Mg-4.5ZnxGd (x=0, 2, 3 and 5) alloys, Journal of Alloys and Compounds, 459 (2008) 274-280.

[19] S. likubo, K. Matsuda, H. Ohtani, Phase stability of long-period stacking structures in Mg-Y-Zn: A first-principles study, Physical Review B, 86 (2012) 054105. 
[20] R. Tanaka, K. Yuge, Thermodynamic stability of Mg-Y-Zn ternary alloys through first-principles, Intermetallics, 72 (2016) 25-29.

[21] Z.-R. Liu, D.-Y. Li, Stability and formation of long period stacking order structure in Mg-based ternary alloys, Computational Materials Science, 103 (2015) 90-96.

[22] J.E. Saal, C. Wolverton, Thermodynamic stability of Mg-based ternary long-period stacking ordered structures, Acta Materialia, 68 (2014) 325-338.

[23] K. Hagihara, Y. Sugino, Y. Fukusumi, Y. Umakoshi, T. Nakano, Plastic Deformation Behavior of Mg12ZnY LPSO-Phase with 14H-Typed Structure, Materials transactions, 52 (2011) 1096-1103.

[24] K. Liu, J. Zhang, H. Lu, D. Tang, L.L. Rokhlin, F.M. Elkin, J. Meng, Effect of the long periodic stacking structure and $\mathrm{W}$-phase on the microstructures and mechanical properties of the $\mathrm{Mg}-8 \mathrm{Gd}-\mathrm{xZn}-0.4 \mathrm{Zr}$ alloys, Materials \& Design, 31 (2010) 210-219.

[25] Q. Wang, K. Liu, Z. Wang, S. Li, W. Du, Microstructure, texture and mechanical properties of asextruded Mg-Zn-Er alloys containing W-phase, Journal of Alloys and Compounds, 602 (2014) 32-39.

[26] D.K. Xu, W.N. Tang, L. Liu, Y.B. Xu, E.H. Han, Effect of Y concentration on the microstructure and mechanical properties of as-cast Mg-Zn-Y-Zr alloys, Journal of Alloys and Compounds, 432 (2007) 129134.

[27] J. Wang, P. Song, X. Zhou, X. Huang, F. Pan, Influence of the morphology of long-period stacking ordered phase on the mechanical properties of as-extruded $\mathrm{Mg}-5 \mathrm{Zn}-5 \mathrm{Y}-0.6 \mathrm{Zr}$ magnesium alloy, Materials Science and Engineering: A, 556 (2012) 68-75.

[28] H.S. Jiang, X.G. Qiao, C. Xu, M.Y. Zheng, K. Wu, S. Kamado, Ultrahigh strength as-extruded Mg10.3Zn-6.4Y-0.4Zr-0.5Ca alloy containing W phase, Materials \& Design, 108 (2016) 391-399.

[29] J. Wang, S. Gao, P. Song, X. Huang, Z. Shi, F. Pan, Effects of phase composition on the mechanical properties and damping capacities of as-extruded $\mathrm{Mg}-\mathrm{Zn}-\mathrm{Y}-\mathrm{Zr}$ alloys, Journal of Alloys and Compounds, 509 (2011) 8567-8572.

[30] F. Masoumi, M. Jahazi, D. Shahriari, J. Cormier, Coarsening and dissolution of $\gamma^{\prime}$ precipitates during solution treatment of AD730 ${ }^{\text {TM }} \mathrm{Ni}$-based superalloy: Mechanisms and kinetics models, Journal of Alloys and Compounds, 658 (2016) 981-995.

[31] F. Masoumi, D. Shahriari, M. Jahazi, J. Cormier, A. Devaux, Kinetics and Mechanisms of gamma' Reprecipitation in a Ni-based Superalloy, Sci Rep, 6 (2016) 28650.

[32] M. Jahazi, A.R. Mashreghi, Dissolution and precipitation kinetics of $\gamma^{\prime}$ in nickel base superalloy Udimet 520, Materials Science and Technology, 18 (2013) 458-462.

[33] G.R. Ebrahimi, A. Momeni, M. Jahazi, P. Bocher, Dynamic Recrystallization and Precipitation in $13 \mathrm{Cr}$ Super-Martensitic Stainless Steels, Metallurgical and Materials Transactions A, 45 (2013) 2219-2231.

[34] M. Celikin, A.A. Kaya, R. Gauvin, M. Pekguleryuz, Effects of manganese on the microstructure and dynamic precipitation in creep-resistant cast Mg-Ce-Mn alloys, Scripta Materialia, 66 (2012) 737-740.

[35] A.S.H. Kabir, M. Sanjari, J. Su, I.-H. Jung, S. Yue, Effect of strain-induced precipitation on dynamic recrystallization in Mg-Al-Sn alloys, Materials Science and Engineering: A, 616 (2014) 252-259.

[36] E. Dogan, S. Wang, M.W. Vaughan, I. Karaman, Dynamic precipitation in Mg-3Al-1Zn alloy during different plastic deformation modes, Acta Materialia, 116 (2016) 1-13.

[37] H. Monajati, F. Zarandi, M. Jahazi, S. Yue, Strain induced $\gamma^{\prime}$ precipitation in nickel base superalloy Udimet 720 using a stress relaxation based technique, Scripta Materialia, 52 (2005) 771-776.

[38] X. Hou, Z. Cao, X. Sun, L. Wang, L. Wang, Twinning and dynamic precipitation upon hot compression of a Mg-Gd-Y-Nd-Zr alloy, Journal of Alloys and Compounds, 525 (2012) 103-109.

[39] D. Choudhuri, S.A. Mantri, T. Alam, S. Banerjee, R. Banerjee, Precipitate-dislocation interaction mediated Portevin-Le Chatelier-like effect in a beta-stabilized Ti-Mo-Nb-Al alloy, Scripta Materialia, 124 (2016) 15-20.

[40] S. Celotto, TEM study of continuous precipitation in Mg-9 wt\%Al-1 wt\%Zn alloy, Acta Materialia, 48 (2000) 1775-1787. 
[41] M. Roostaei, M. Shirdel, M.H. Parsa, R. Mahmudi, H. Mirzadeh, Microstructural evolution and grain growth kinetics of GZ31 magnesium alloy, Materials Characterization, 118 (2016) 584-592.

[42] A. Deschamps, M. Garcia, J. Chevy, B. Davo, F. De Geuser, Influence of Mg and Li content on the microstructure evolution of AICuLi alloys during long-term ageing, Acta Materialia, 122 (2017) 32-46.

[43] S.J. Liu, G.Y. Yang, S.F. Luo, W.Q. Jie, Microstructure and mechanical properties of sand mold cast $\mathrm{Mg}-4.58 \mathrm{Zn}-2.6 \mathrm{Gd}-0.18 \mathrm{Zr}$ magnesium alloy after different heat treatments, Journal of Alloys and Compounds, 644 (2015) 846-853.

[44] F. Lu, A. Ma, J. Jiang, D. Yang, D. Song, Y. Yuan, J. Chen, Effect of multi-pass equal channel angular pressing on microstructure and mechanical properties of Mg97.1Zn1Gd1.8Zr0.1 alloy, Materials Science and Engineering: A, 594 (2014) 330-333.

[45] A. Srinivasan, Y. Huang, C.L. Mendis, C. Blawert, K.U. Kainer, N. Hort, Investigations on microstructures, mechanical and corrosion properties of Mg-Gd-Zn alloys, Materials Science and Engineering: A, 595 (2014) 224-234.

[46] S. Zhang, G.Y. Yuan, C. Lu, W.J. Ding, The relationship between (Mg,Zn)3RE phase and 14H-LPSO phase in Mg-Gd-Y-Zn-Zr alloys solidified at different cooling rates, Journal of Alloys and Compounds, 509 (2011) 3515-3521.

[47] X. Zhang, Y. Wu, Y. Xue, Z. Wang, L. Yang, Biocorrosion behavior and cytotoxicity of a Mg-Gd-Zn-Zr alloy with long period stacking ordered structure, Materials Letters, 86 (2012) 42-45.

[48] J.S. Zhang, W.B. Zhang, X.Q. Ruan, L.P. Bian, W.L. Cheng, H.X. Wang, C.X. Xu, Effect of zirconium on the microstructure and mechanical properties of long period stacking ordered Mg96Gd3Zn1 alloy, Materials Science and Engineering: A, 560 (2013) 847-850.

[49] Z.Z. Peng, X.H. Shao, Q.Q. Jin, C.H. Li, X.L. Ma, Deformation induced precipitation of nano-particles in an Mg88Co5Y7 alloy, Scripta Materialia, 116 (2016) 57-61.

[50] E. Oñorbe, G. Garcés, P. Pérez, P. Adeva, Effect of the LPSO volume fraction on the microstructure and mechanical properties of Mg-Y2X -Zn X alloys, Journal of Materials Science, 47 (2011) 1085-1093. [51] M. Yamasaki, K. Hagihara, S.-i. Inoue, J.P. Hadorn, Y. Kawamura, Crystallographic classification of kink bands in an extruded $\mathrm{Mg}-\mathrm{Zn}-\mathrm{Y}$ alloy using intragranular misorientation axis analysis, Acta Materialia, 61 (2013) 2065-2076.

[52] Y.J. Wu, X.Q. Zeng, D.L. Lin, L.M. Peng, W.J. Ding, The microstructure evolution with lamellar 14Htype LPSO structure in an Mg96.5Gd2.5Zn1 alloy during solid solution heat treatment at 773K, Journal of Alloys and Compounds, 477 (2009) 193-197.

[53] L. Zheng, C. Liu, Y. Wan, P. Yang, X. Shu, Microstructures and mechanical properties of Mg-10Gd6Y-2Zn-0.6Zr(wt.\%) alloy, Journal of Alloys and Compounds, 509 (2011) 8832-8839.

[54] M. Yamasaki, M. Sasaki, M. Nishijima, K. Hiraga, Y. Kawamura, Formation of $14 \mathrm{H}$ long period stacking ordered structure and profuse stacking faults in $\mathrm{Mg}-\mathrm{Zn}-\mathrm{Gd}$ alloys during isothermal aging at high temperature, Acta Materialia, 55 (2007) 6798-6805.

[55] W.W. Hu, Z.Q. Yang, H.Q. Ye, Cottrell atmospheres along dislocations in long-period stacking ordered phases in a Mg-Zn-Y alloy, Scripta Materialia, 117 (2016) 77-80.

[56] P. Yang, P. Li, L.-Q. Zhang, X.-L. Wang, H. Wang, X.-F. Song, F.-W. Xie, Uniaxial stress influence on lattice, band gap and optical properties of n-type ZnO: first-principles calculations, Chinese Physics B, 21 (2012) 016803.

[57] S.G. Chowdhury, Effect of boron in Ni3Al: Structural-transformation induced ductilization, Philosophical magazine letters, 74 (1996) 327-330.

[58] J. Marro, R. Toral, A.M. Zahra, Time evolution of the excess energy in supersaturated solid solutions: microcalorimetric experiments, computer simulations and theory, Journal of Physics C: Solid State Physics, 18 (1985) 1377.

[59] D. Schryvers, W. Tirry, Z.Q. Yang, Measuring strain fields and concentration gradients around Ni4Ti3 precipitates, Materials Science and Engineering: A, 438-440 (2006) 485-488. 
[60] M. Militzer, W.P. Sun, J.J. Jonas, Modelling the effect of deformation-induced vacancies on segregation and precipitation, Acta Metallurgica et Materialia, 42 (1994) 133-141.

[61] P.G. McCormigk, A model for the Portevin-Le Chatelier effect in substitutional alloys, Acta Metallurgica, 20 (1972) 351-354.

[62] R.C. Picu, G. Vincze, F. Ozturk, J.J. Gracio, F. Barlat, A.M. Maniatty, Strain rate sensitivity of the commercial aluminum alloy AA5182-O, Materials Science and Engineering: A, 390 (2005) 334-343. 